\title{
An overview of the hooking mortality of elasmobranchs caught in a swordfish pelagic longline fishery in the Atlantic Ocean
}

\author{
Rui CoelHo ${ }^{1,2, a}$, Joana FernandeZ-CARVALHO ${ }^{1}$, Pedro G. Lino ${ }^{1}$ and Miguel N. SANTOS ${ }^{1}$ \\ ${ }^{1}$ Instituto Português do Mar e da Atmosfera, I.P. (IPMA), Avenida 5 de Outubro s/n, 8700-305 Olhão, Portugal \\ 2 Centro de Ciências do Mar (CCMAR), Universidade do Algarve, Campus de Gambelas FCT Ed.7, 8005-170 Faro, Portugal
}

Received 6 February 2012; Accepted 24 September 2012

\begin{abstract}
Hooking (or "at-haulback") fishing mortality was analysed in elasmobranchs captured by Portuguese longliners targeting swordfish in the Atlantic Ocean. Information was collected by on-board fishery observers who monitored 834 longline fishing sets between August 2008 and December 2011, and recorded information on 36067 elasmobranch specimens from 21 different taxa. The hooking mortality proportions were species-specific, with some species having relatively high percentages of live specimens at time of haulback (e.g., blue shark, crocodile shark, pelagic stingray, manta, devil and eagle rays), while others had higher percentages of dead specimens (e.g., smooth hammerhead, silky shark, bigeye thresher). For the most captured species (Prionace glauca, Pseudocarcharias kamoharai, Isurus oxyrinchus and Alopias superciliosus), logistic generalized linear models (GLMs) were carried out to compare the mortality rates between sexes, specimen sizes and the regions of operation of the fleet. The sex-specific proportions of hooking mortality were significantly different for blue and crocodile sharks, with the males of both species having higher proportions of hooking mortality than the females. Specimen size was significant for predicting the hooking mortality for blue and shortfin mako sharks: in both cases, the larger specimens had lower odds of dying due to the fishing process. There were differences in the hooking mortality depending on the region of operation of the fleet, but those differences were also species-specific. For blue and crocodile sharks, the hooking mortality was higher in the Equatorial and southern Atlantic areas (when compared to the NE Atlantic region), while the opposite was observed for the shortfin mako, with lower mortality rates in the NE tropical area compared with the other regions. The results presented in this paper can be integrated into future ecological risk assessment analysis for pelagic elasmobranchs. Furthermore, the new information can be used to evaluate the impact of recent recommendations prohibiting the retention of some vulnerable elasmobranch species.
\end{abstract}

Keywords: Hooking mortality / pelagic longline fisheries / bycatch / discards / sharks / rays / Atlantic Ocean

\section{Introduction}

In the Atlantic Ocean, several pelagic elasmobranch species are commonly caught as bycatch in pelagic swordfish longline fisheries (e.g., Buencuerpo et al. 1998; Petersen et al. 2009). The natural mortality rates of these species are usually low, so increased fishing mortality may have severe consequences for their populations (Dulvy et al. 2008), with declines occurring even at relatively low levels of fishing mortality (Smith et al. 1998; Stevens et al. 2000). As many bycatch species are discarded by these fisheries, information on hooking (also known as "at-haulback") fishing mortality is important for the evaluation of the impacts of these fisheries on the species captured and the pelagic ecosystem.

Previous studies have focused on elasmobranch fishing mortality. However, most were carried out for coastal trawl

\footnotetext{
${ }^{a}$ Corresponding author: rpcoelho@ipma.pt
}

fisheries [e.g., spurdog (Squalus acanthias) by Mandelman and Farrington (2007); small-spotted catshark (Scyliorhinus canicula) by Rodríguez-Cabello et al. (2005); and Rajidae skates by Enever et al. (2009)]. In terms of longlines, Morgan and Burgess (2007) and Morgan and Carlson (2010) analysed hooking mortality of coastal sharks caught in the U.S. bottom longline fishery, while Afonso et al. (2011) analysed fishing gear modifications that could reduce elasmobranch mortality in bottom and pelagic longlines in Brazil. For pelagic elasmobranchs captured in longline fisheries, previous studies addressing hooking mortality have focused mainly on the blue shark (Prionace glauca). Campana et al. (2009) carried out a comprehensive study of blue shark caught in the NW Atlantic (Canadian fishery), including both the short-term hooking mortality recorded at haulback and the post-release longterm mortality recorded by satellite telemetry. Also in the NW Atlantic, Diaz and Serafy (2005) analysed factors that 
could affect the numbers of blue sharks in good enough condition for live release, using data from the U.S. Atlantic pelagic fishery observer program. In the Pacific Ocean, Moyes et al. (2006) predicted post-release survival of blue sharks, Musyl et al. (2011) analysed the post-release survival of five pelagic elasmobranch species, and Walsh et al. (2009) analysed mortality of several shark species for the Hawaii-based longline fishery, including deep and shallow water sets.

Knowledge on hooking mortality can be used to evaluate conservation and management measures, including the prohibition to retain particular vulnerable species, such as those recently implemented by some tuna Regional Fisheries Management Organizations (RFMOs). These include the recent management recommendations by the International Commission for the Conservation of Atlantic Tunas (ICCAT), which implemented mandatory discards of the bigeye thresher (ICCAT Rec. 2009/07), oceanic whitetip (ICCAT Rec. 2010/07), hammerheads (ICCAT Rec. 2010/08) and silky shark (ICCAT Rec. 2011/08). However, both the athaulback/hooking mortality and the long-term post-release survivorship remain largely unknown for these species, so the impact of such measures also remains unknown.

Hooking mortality estimations are also important as they can be incorporated into stock assessment studies. Cortés et al. (2010) conducted an Ecological Risk Assessment (ERA) for eleven pelagic elasmobranch species in the Atlantic Ocean, and determined their relative productivity/susceptibility in order to rank and compare the vulnerability of the species caught in the fishery. More recently, Arrizabalaga et al. (2011) carried out an ERA analysis that included all bycatch groups captured in pelagic longline tuna fisheries in the Atlantic Ocean. One parameter that can be used and included in such types of assessment (in the susceptibility component of the analysis) is the probability of survival after capture, which can be partially inferred from the proportions of species-specific hooking mortality.

The aim of this paper is to explore hooking mortality (recorded at haulback, during fishing gear retrieval) in a pelagic longline fishery targeting swordfish in the Atlantic Ocean and by-catching pelagic sharks. The main objective of the study was to present species-specific proportions of hooking mortality, while a secondary objective was to explore relationships between the hooking mortality and some possible explanatory variables, such as specimen size, sex and region of operation of the fishery.

\section{Materials and methods}

Data were collected from 18 fishing trips and 5 different fishing vessels by IPMA, IP (Portuguese Marine and Atmospheric Institute) fishery observers' onboard Portuguese longliners targeting swordfish along the Atlantic Ocean. Data were collected between August 2008 and December 2011, from a total of 834 longline sets, corresponding to 1078200 hooks deployed.

The fishery covers a wide area of the Atlantic Ocean in both hemispheres. The study area was divided into four areas of fleet operation: the temperate northeast Atlantic, tropical northeast Atlantic, equatorial, and southern Atlantic regions
(Fig. 1). Many characteristics of the vessels of the fleet are similar between regions. For example, the targeted species is mainly swordfish and, to a lesser extent, tropical tunas, with fishing conducted at depths of 20-50 m below the surface, with gear deployment beginning at around 17:00 $\mathrm{h}$ and haulback starting the next day from about 06:00 h. The traditional hooks used by the fishery are stainless steel J-style hooks, and the baits are usually either squid (Illex spp.) or mackerel (Scomber spp.). Both monofilament and wire branch lines are used, but only one type is used per fishing set. However, some differences do exist within the fleet, which is the reason why the study area was divided into the four regions mentioned above. For example, the vessels that operate in the NE Atlantic temperate region (closer to mainland Portugal and the Azores archipelago) tend to be smaller in size and mostly do not have freezing capacity (the catch is usually refrigerated); therefore, they make shorter trips of a few days to weeks. In contrast, the vessels that operate mainly in the more distant regions of the equatorial and southern Atlantic are usually larger vessels with freezing capacity that tend to make longer trips of up to four months in duration.

For every specimen caught, the onboard fishery observers recorded usually the species level, except for manta, devil and eagle rays, and specimen size (FL, fork length for sharks and DL, disk length for the manta, devil and eagle rays, both measured to the nearest lower $\mathrm{cm}$ ) and condition at haulback (alive or dead at time of fishing gear retrieval). For each fishing set, information on the date, geographical coordinates (latitude and longitude) and number of hooks used was recorded. The condition of the sharks at fishing gear retrieval (alive or dead) was categorized based on any responsiveness from the sharks indicating that specimens were alive.

Species-specific quantities of live and dead specimens were recorded at the time of capture, and their respective percentages calculated. These percentages were calculated for both sexes combined, but also by sex for the most abundant species, namely the blue shark (Prionace glauca), crocodile shark (Pseudocarcharias kamoharai), shortfin mako (Isurus oxyrinchus) and bigeye thresher (Alopias superciliosus). These four species were selected because of their larger sample sizes (>1000 specimens).

The size distributions of these four most abundant species were compared between regions and sexes. For the comparison between regions, Kruskal-Wallis (KW) tests were used, while the comparison between sexes was carried out with MannWhitney and 2-sample Kolmogorov-Smirnov (K-S) tests. Non-parametric tests were used rather than parametric ones because the data was not normally distributed (as shown by Lilliefors tests) and the variances were heterogeneous between groups (as shown by Levene tests).

The relationship between hooking mortality and specimen size was assessed for the four species. Multivariate generalized linear models (GLM) with binomial error structure and a logit link function (logistic models) were applied to the mortality data using specimen size (FL, in $\mathrm{cm}$ ), sex and region as the explanatory variables. The event of interest considered in these models was the specimen mortality (coded with 1), while live specimens at haulback were coded with 0 . The significance of the explanatory variables was determined with Wald statistics 


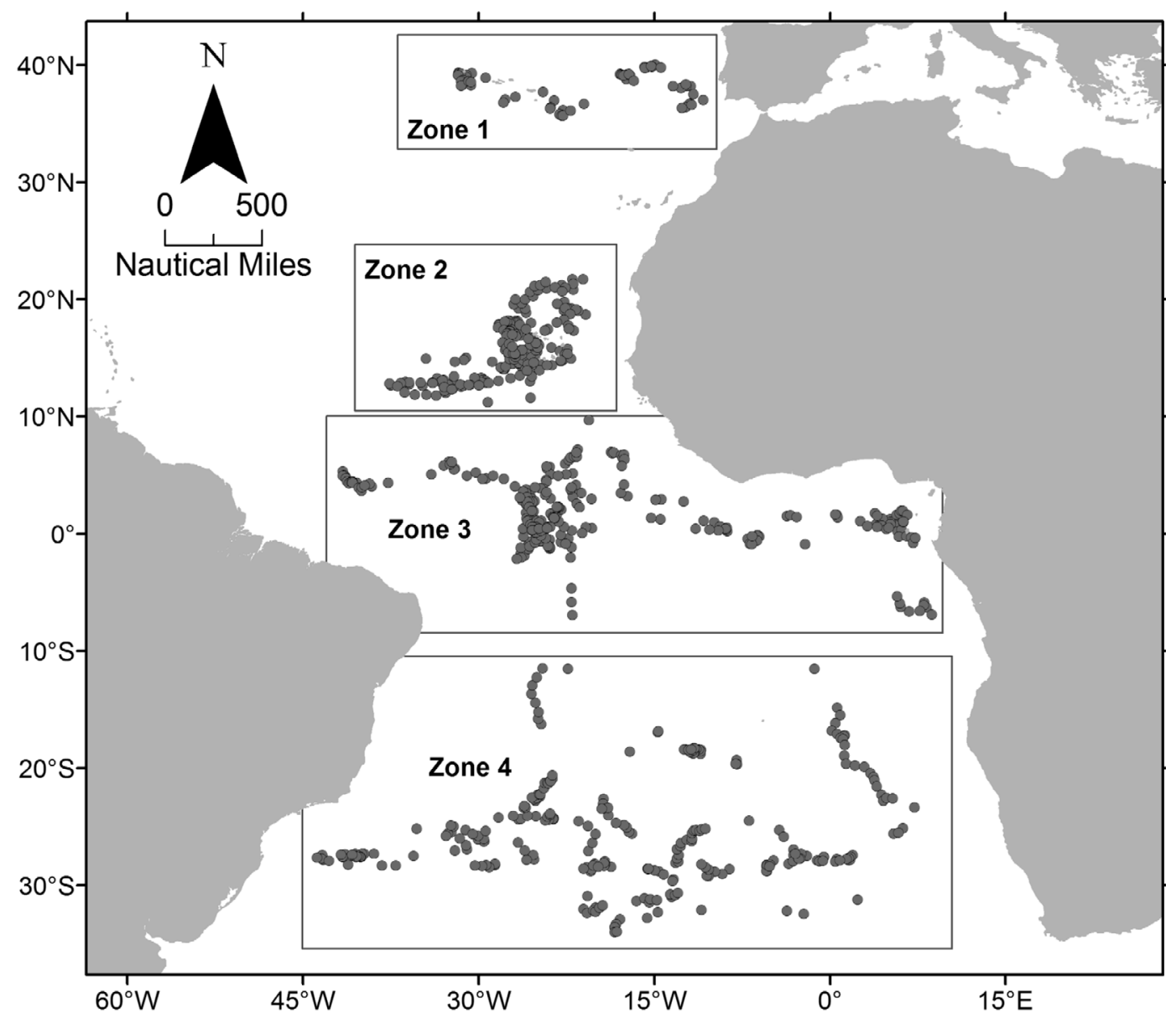

Fig. 1. Location of the longline fishing sets analysed in this study, showing the four areas of operation of the Portuguese longline fleet that were considered for the analysis: Zone 1: temperate NE Atlantic; Zone 2: tropical NE Atlantic: Zone 3: equatorial; Zone 4: southern Atlantic Ocean.

and likelihood ratio tests, comparing nested models. The linearity of the continuous explanatory variable (in this case the specimen size) with the linear predictor was assessed with generalized additive model (GAM) plots. After fitting the models for each species, the odds-ratios with the respective $95 \%$ confidence intervals were calculated. For the categorical variables, the odds-ratios were calculated with reference to a baseline level for each variable: in this case region 1 (northeast temperate) for the region variable, and females for the sex. For the continuous variable, the odds-ratios were calculated in terms of changes in the mortality rates for a $10 \mathrm{~cm}$ increase in specimen FL.

All statistical analyses were carried out with the "R Project for Statistical Computing" version 2.14.0 (R Development Core Team 2011). Most analysis carried out are available under the core R program, except the contingency table analysis that was carried out using the "gmodels" library (Warnes et al. 2011), and the GAM plots that were created with "gam" library (Hastie 2011).

\section{Results}

During this study, data on a total of 36067 specimens from 21 different taxa were recorded (Table 1). The blue shark was the most commonly captured species, representing $84 \%$ of the total elasmobranch catch, followed by the crocodile shark (5\%), shortfin mako (4\%) and bigeye thresher (3\%) (Fig. 2). The average catch per unit effort (CPUE) for the main target species of the fishery (swordfish) was 12.8 specimens per 1000 hooks during the study period while, and considering the commonest shark bycatch species, it was 27.9 per 1000 hooks for the blue shark, 1.5 per 1000 hooks for the crocodile, and 1.3 per 1000 hooks for the shortfin mako (Fig. 2). Of the 36067 specimens that were caught during the study period, information on hooking mortality was recorded for most: 35502 specimens, representing $98.4 \%$ of the sample (Table 1).

The length of the mainline and number of hooks used per set varied among vessels and fishing sets according to each particular vessel's operating capacity and the specific sea conditions during the fishing operations. On average, for the whole fleet combined, 1293 hooks were used per set $(\mathrm{SD}=187)$; although, considering the four separate regions, there was a tendency for an increase in effort for the more distant areas. Specifically, the mean effort per set was 924 (79), 1216 (105), 1334 (106) and 1385 (195) hooks deployed per set for regions $1,2,3$ and 4, respectively.

In terms of the condition of the animals at time of haulback, it was possible to determine significant 
Table 1. Descriptive statistics of elasmobranchs caught and analysed for this study. Both the scientific names and the FAO letter codes are given. Sample size refers to the number of specimens caught and sampled of each species. Hook mortality refers to the species-specific hooking mortality (\% dead). Size data is given in fork length (FL, cm) for sharks, and disk length (DL, cm) for the manta, devil and eagle rays, with values of the minimum (Min), maximum (Max), mean size (Mean) and standard deviation (SD).

\begin{tabular}{|c|c|c|c|c|c|c|c|c|}
\hline \multirow{2}{*}{$\begin{array}{l}\text { FAO } \\
\text { Code }\end{array}$} & \multirow[b]{2}{*}{ Taxon } & \multirow[b]{2}{*}{ Common name } & \multirow[b]{2}{*}{$\begin{array}{l}\text { Sample } \\
\text { size }(n)\end{array}$} & \multirow{2}{*}{$\begin{array}{c}\text { Hook } \\
\text { mortality } \\
(\% \text { dead })\end{array}$} & \multicolumn{4}{|c|}{ Size (FL or DL) } \\
\hline & & & & & Min & Max & Mean & SD \\
\hline $\mathrm{BSH}$ & Prionace glauca & Blue shark & 30168 & 14.3 & 40 & 315 & 197.1 & 34.5 \\
\hline PSK & Pseudocarcharias kamoharai & Crocodile shark & 1621 & 13.3 & 38 & 117 & 83.5 & 9.3 \\
\hline SMA & Isurus oxyrinchus & Shortfin mako & 1414 & 35.6 & 66 & 305 & 168.8 & 35.4 \\
\hline BTH & Alopias superciliosus & Bigeye thresher & 1061 & 50.6 & 80 & 265 & 167.0 & 29.5 \\
\hline PLS & Pteroplatytrygon violacea & Pelagic stingray & 396 & 1.0 & 30 & 103 & 46.9 & 15.0 \\
\hline SPZ & Sphyrna zygaena & Smooth hammerhead & 372 & 71.0 & 136 & 275 & 197.5 & 24.9 \\
\hline FAL & Carcharhinus falciformis & Silky shark & 310 & 55.8 & 61 & 242 & 130.1 & 43.2 \\
\hline OCS & Carcharhinus longimanus & Oceanic whitetip shark & 281 & 34.2 & 63 & 227 & 128.0 & 33.7 \\
\hline LMA & Isurus paucus & Longfin mako & 168 & 30.7 & 68 & 266 & 145.5 & 43.1 \\
\hline MAN & Mobulidae & Mantas and devil rays & 145 & 1.4 & 55 & 240 & 104.8 & 90.2 \\
\hline GAC & Galeocerdo cuvier & Tiger shark & 36 & 2.9 & 134 & 300 & 197.5 & 41.3 \\
\hline GAG & Galeorhinus galeus & Tope shark & 25 & 0.0 & 80 & 175 & 95.2 & 19.7 \\
\hline SPL & Sphyrna lewini & Scalloped hammerhead & 21 & 57.1 & 160 & 240 & 194.9 & 19.3 \\
\hline EAG & Myliobatidae & Eagle rays & 19 & 0.0 & 30 & 50 & 41.7 & 10.4 \\
\hline CCA & Carcharhinus altimus & Bignose shark & 11 & 60.0 & 78 & 110 & 95.3 & 8.9 \\
\hline POR & Lamna nasus & Porbeagle & 10 & 30.0 & 129 & 236 & 192.1 & 33.8 \\
\hline ALV & Alopias vulpinus & Thresher & 3 & 66.7 & 200 & 220 & 212.3 & 10.8 \\
\hline SPM & Sphyrna mokarran & Great hammerhead & 3 & 0.0 & 165 & 251 & 217.3 & 45.9 \\
\hline GNC & Ginglymostoma cirratum & Nurse shark & 1 & 0.0 & & & & \\
\hline GUP & Centrophorus granulosus & Gulper shark & 1 & 100.0 & 72 & 72 & 72.0 & \\
\hline ISB & Isistius brasiliensis & Cookie cutter shark & 1 & 0.0 & 48 & 48 & 48.0 & \\
\hline
\end{tabular}

species-specific differences (Table 1, Fig. 2). Species such as the blue and crocodile sharks had relatively low percentages of dead specimens at haulback (than less $15 \%$ ), while for the smooth hammerhead, silky shark and bigeye thresher, the percentages of dead specimens at haulback were generally higher than $50 \%$ (Fig. 2). In particular, the smooth hammerhead had a very high hooking mortality rate, with $71 \%$ of the specimens caught being dead at haulback. In contrast, all the batoids (pelagic stingray, manta, devil and eagle rays) had very low percentages of dead specimens at haulback $(\leqslant 2 \%)$.

The size distributions of the four most frequently captured species varied significantly between regions (Fig. 3), as shown by Kruskal-Wallis tests (blue shark: $\mathrm{KW}=8206.5, d f=3$, $p<0.01$; crocodile shark: $\mathrm{KW}=57.9, d f=2, p<0.01$; shortfin mako: $\mathrm{KW}=53.9, d f=3, p<0.01$; bigeye thresher: $\mathrm{KW}=140.7, d f=3, p<0.01)$.

For three of the four species there were significant differences in the size distribution between sexes (Fig. 4). Specifically, the size distribution was significantly different between male and female blue sharks (2-sample K-S test: $D=0.099$, $p<0.01$ ), with the median size of males smaller than that of females (Mann-Whitney test: $W=109392283, p<0.01$ ). For the bigeye thresher, the size distribution between sexes was also significantly different (2-sample K-S test: $D=0.23$, $p<0.01)$ but the median size of males was significantly larger than that of females (Mann-Whitney test: bigeye thresher: $W=73496, p<0.01)$.
For the blue and shortfin mako sharks there was a general trend of decreasing mortality with increasing specimen size (Fig. 5). For the crocodile shark and bigeye thresher, however, the effects of specimen size did not seem to influence the hooking mortality rates, as relatively similar rates were observed for all sizes (Fig. 5). In terms of the multivariate logistic models, the significant variables in each model varied depending on the species. Specimen size was significant for the blue and shortfin mako sharks, region was significant for the blue, shortfin mako and crocodile sharks, and sex was significant for the blue and crocodile sharks (Table 2). For the bigeye thresher, none of the variables considered were significant, meaning that there were no differences in the mortality rates depending on specimen size, region or specimen sex (Table 2).

Multivariate model interpretation using odds-ratios for the blue shark showed that hooking mortality decreased by $14 \%$ for an increase of $10 \mathrm{~cm}$ in size (FL), with the $95 \%$ confidence interval between $13 \%$ and $15 \%$ (Table 3 ). Likewise, the effects of size on the shortfin mako also showed a negative trend, with hooking mortality decreasing by $6 \%$ for an increase of $10 \mathrm{~cm}$ FL, with the $95 \%$ confidence interval between $3 \%$ and $9 \%$ (Table 3). Region had an effect on blue and crocodile sharks as the mortality rates in the equatorial and southern Atlantic areas were higher than those in the northeastern Atlantic, while the opposite effect was observed for the shortfin mako, with lower mortality rates in the southern regions (Table 3). Finally, in this multivariate modeling approach, the effects of sex were 


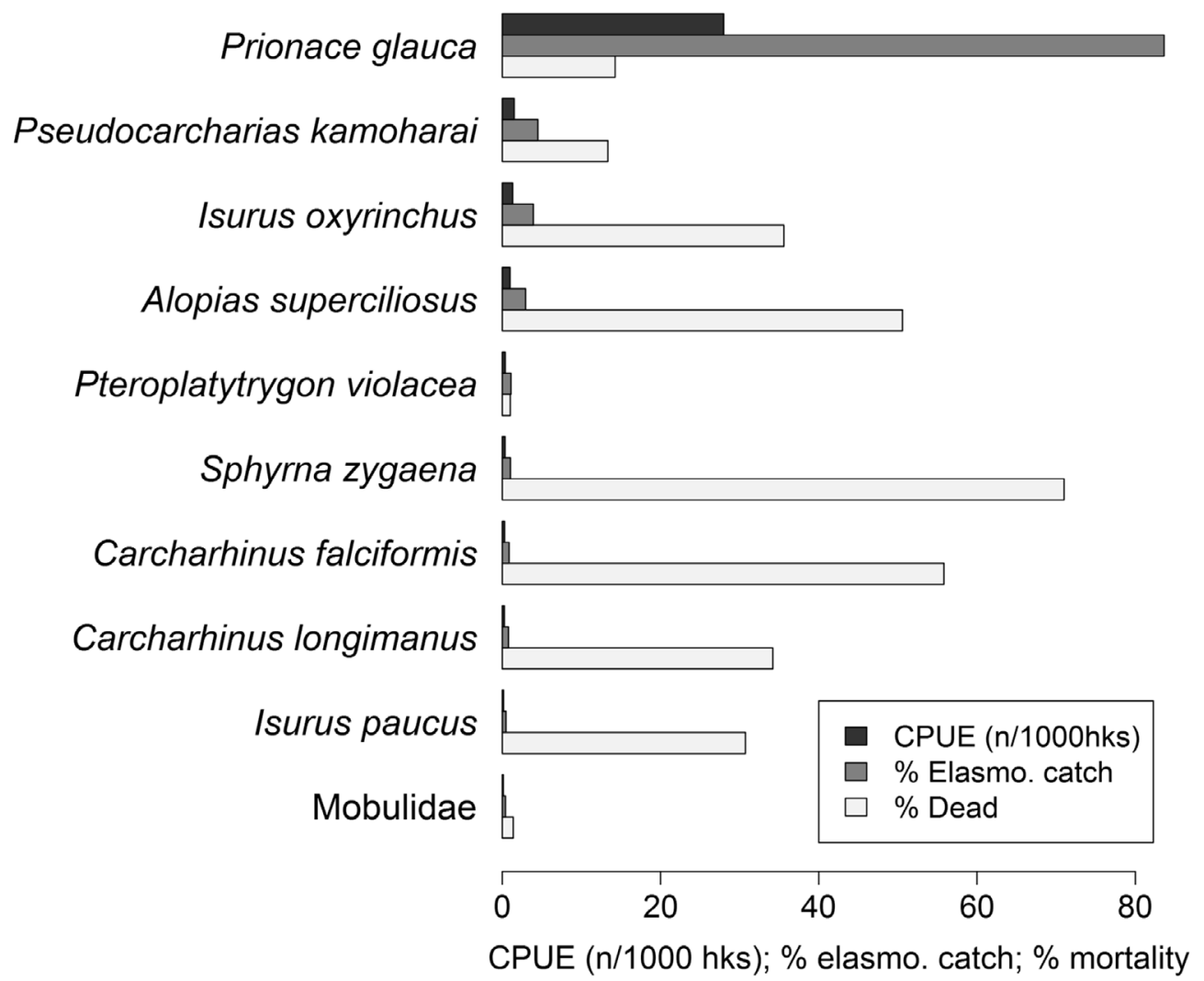

Fig. 2. Species-specific CPUEs ( $n / 1000$ hooks), percentages of each species within the total elasmobranch catch, and species-specific percentages of dead specimens at haulback. Only taxa with large sample sizes $(n>100)$ are plotted.

significant for blue and crocodile sharks, with the males of both species having higher odds of dying than females in both cases (Table 3).

\section{Discussion}

During this study it was possible to determine that the hooking mortality percentages of pelagic elasmobranchs caught in pelagic longline fisheries are species-specific, and that management options therefore need to consider those specificities. The batoids, including the pelagic stingray, manta, devil and eagle rays tend to have very low percentages of dead specimens at haulback, with most batoids therefore being discarded alive. Some shark species, such as blue and crocodile sharks, also have relatively low percentages of dead specimens, with hooking mortalities generally lower than $15 \%$. In contrast, species such as the smooth hammerhead, silky shark and bigeye thresher had higher hooking mortality rates, usually with more than $50 \%$ of specimens captured (and discarded) dead. The smooth hammerhead seems to be a particularly vulnerable species in this respect, as $71 \%$ of the specimens are captured already dead.

Campana et al. (2009) about blue sharks caught by the Canadian longline fishery in the northwest Atlantic Ocean, concluded that short-term hooking mortality was in the $12-13 \%$ range (measured by fishery observers), which is very close to our study (14\%). However, these authors stated that hooking mortality might be underestimated: it could be around $20 \%$ in blue sharks in the Canadian fishery. It is expected that, at least for the blue shark, our assessment of hooking mortality may be underestimated in the Portuguese fishery as well. Additionally, we only considered the short-term hooking mortality that resulted from the actual fishing process. Some specimens may be discarded alive but with severe trauma that may result in long-term post-release mortality, not accounted for in this study. To measure such effects, the deployment of satellite telemetry tags would be needed, as they allow sharks' vertical and horizontal movements to be tracked for weeks or months after they are released. Therefore, the values presented in this paper should be regarded as the minimum mortality values for each species or taxon caused by the fishing process, and these values may be increased by long-term post-release mortality.

The type of hook needs to be taken into account in hooking mortality studies. The Portuguese swordfish longline fishery traditionally uses J-style hooks, and the values reported in our study therefore refer to that specific type of hook. Other fisheries may use other types of hooks (e.g., circle hooks, tuna hooks, or a combination of different types). For some species, including the blue shark, J-style hooks have already been shown to cause higher hooking mortality rates than circle hooks (Carruthers et al. 2009); however, for the elasmobranch species that are most frequently discarded (e.g., bigeye thresher, crocodile shark, pelagic stingray and manta rays) Coelho et al. (2012) showed that the hook style (J-style vs. circle hooks) was unrelated to hooking mortality. 

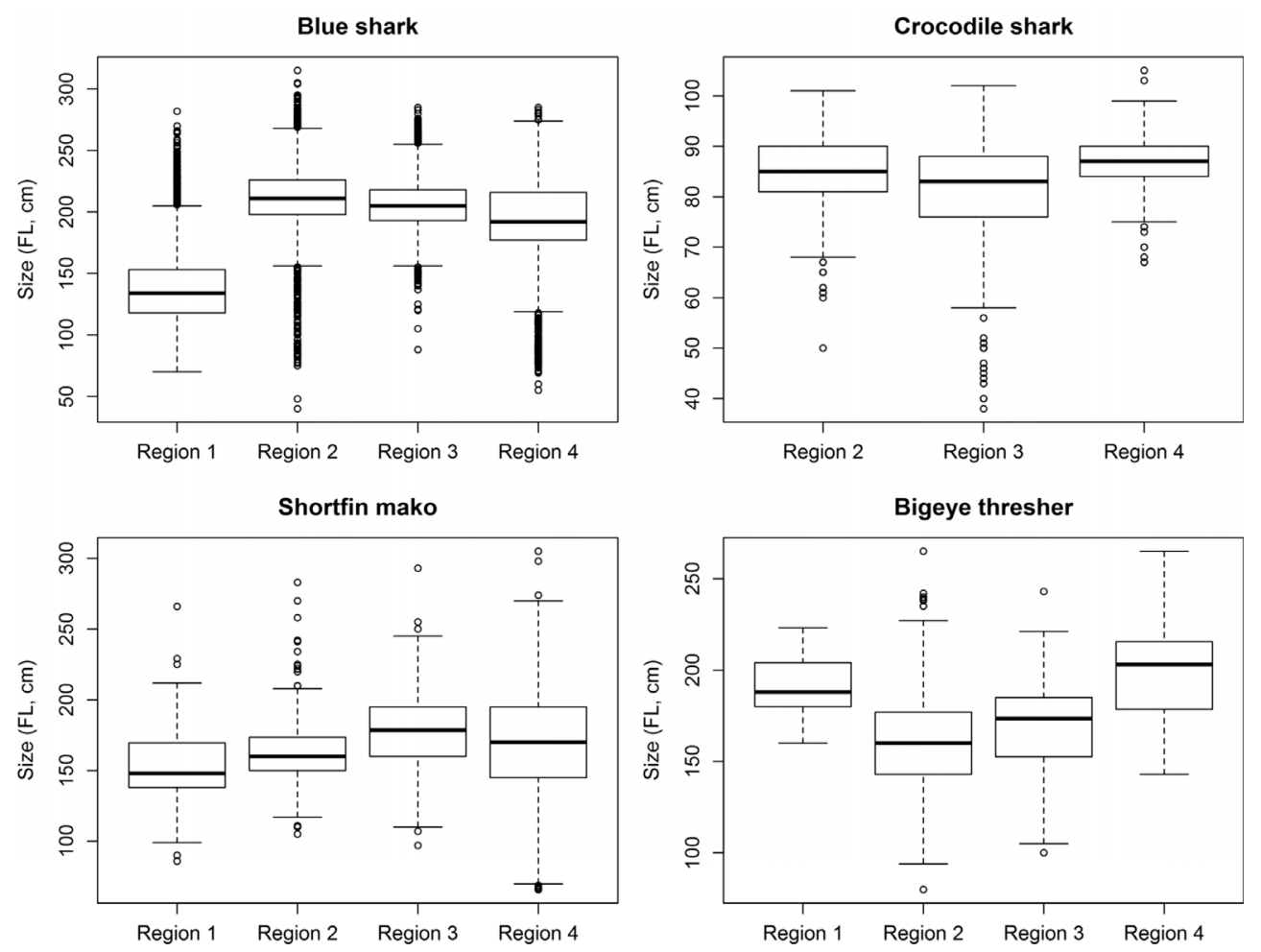

Fig. 3. Size distribution of the four most frequently captured elasmobranch species $(n>1000)$ per region in the study area. In each boxplot, the central line represents the median, the box represents the 0.25 and 0.75 quartiles, the whiskers represent the non-outlier range, and the dots represent the outliers.
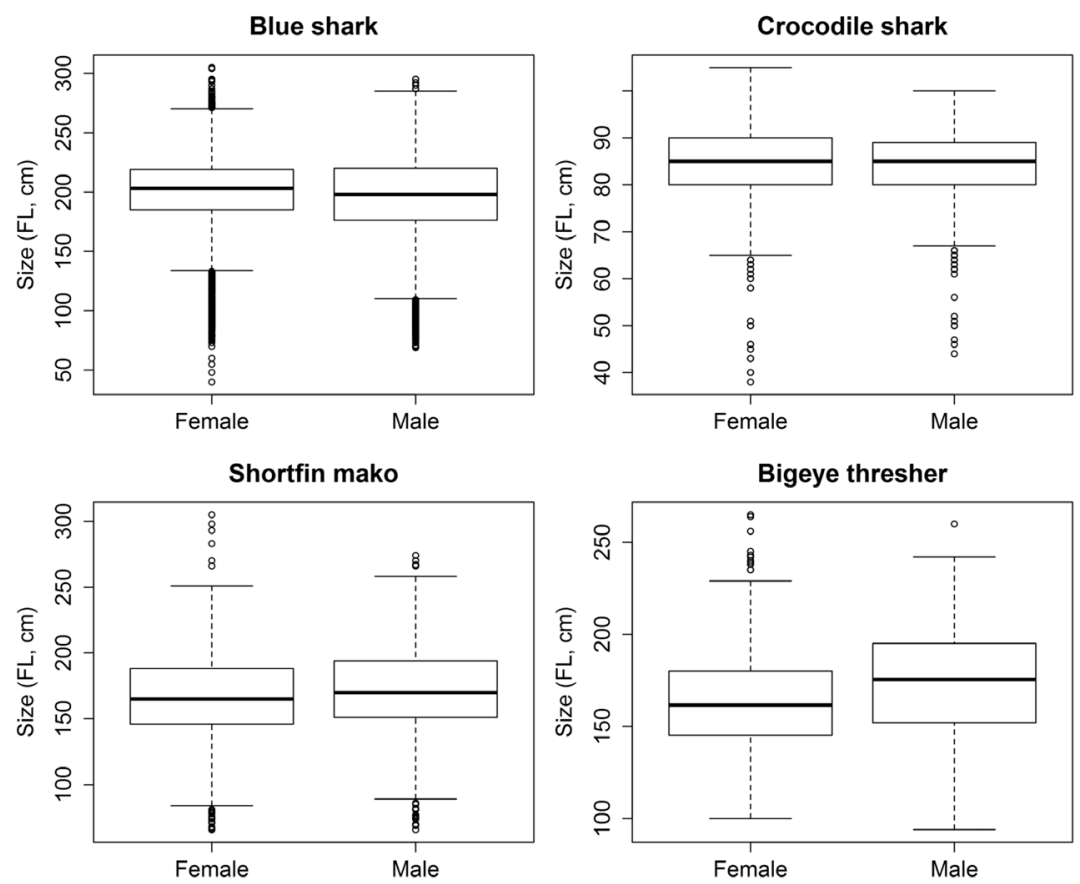

Fig. 4. Size distribution of males and females for the four most frequently captured elasmobranch species $(n>1000)$. In each boxplot, the central line represents the median, the box represents the 0.25 and 0.75 quartiles, the whiskers represent the non-outlier range, and the dots represent the outliers. 
Blue shark

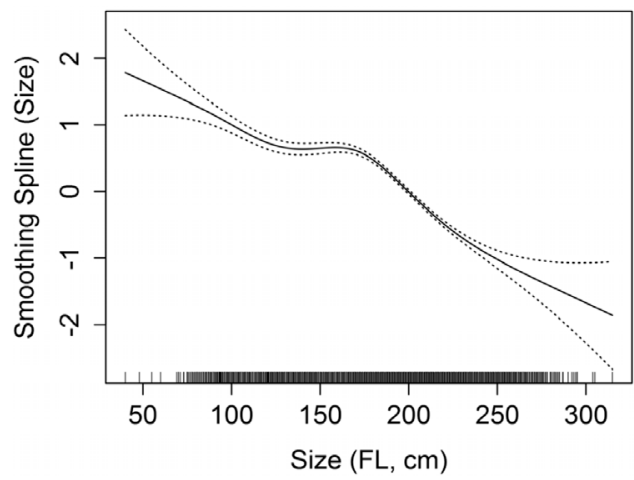

Shortfin mako

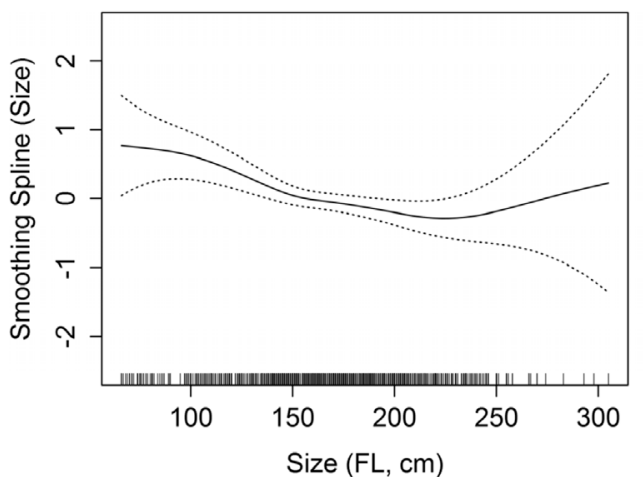

Crocodile shark

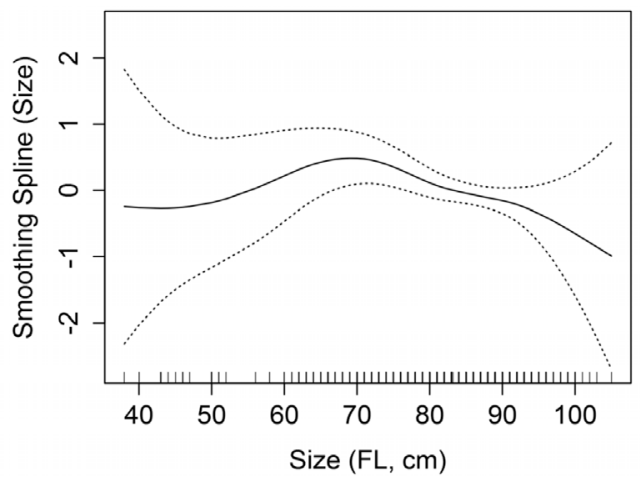

Bigeye thresher

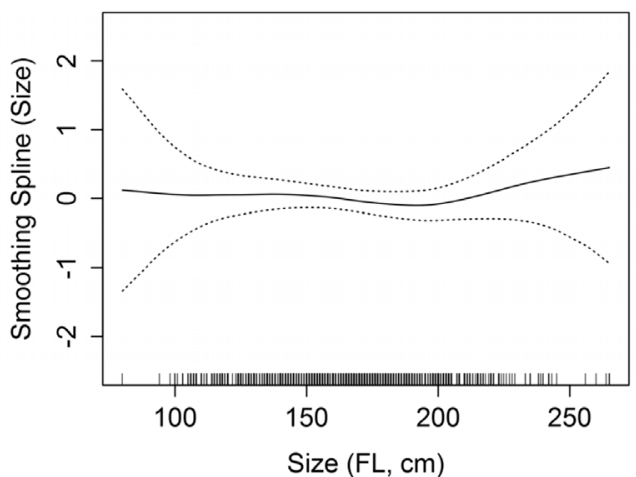

Fig. 5. Generalized additive model (GAM) plots with the effects of specimen size (FL, cm) on hooking mortality. The analysis is presented for the four most frequently captured elasmobranch species $(n>1000)$.

Table 2. Effects of specimen size, region and sex on the hooking mortality rates of the four most frequently captured elasmobranch species. Degrees of freedom needed to estimate parameters for each variable $(d f)$, the deviance explained by each variable (Dev.), and the residual degrees of freedom (Resid. $d f$ ) and deviance (Resid. Dev) after including each parameter are presented. The significance of including each variable in the analysis is given by the $p$-value of the Chi-square test.

\begin{tabular}{|c|c|c|c|c|c|}
\hline Variable & $d f$ & Dev. & Resid. $d f$ & Resid. Dev. & $p$-value \\
\hline \multicolumn{6}{|c|}{ Prionace glauca $(\mathrm{BSH})$} \\
\hline Null & & & 28329 & 23294 & \\
\hline Size & 1 & 869.9 & 28328 & 22424 & $<0.01$ \\
\hline Region & 3 & 308.5 & 28325 & 22116 & $<0.01$ \\
\hline Sex & 1 & 24.1 & 28324 & 22092 & $<0.01$ \\
\hline \multicolumn{6}{|c|}{ Pseudocarcharias kamoharai (PSK) } \\
\hline Null & & & 954 & 953 & \\
\hline Size & 1 & 0.04 & 953 & 953 & 0.84 \\
\hline Region & 2 & 37.8 & 951 & 915 & $<0.01$ \\
\hline Sex & 1 & 13.6 & 950 & 902 & $<0.01$ \\
\hline \multicolumn{6}{|c|}{ Isurus oxyrinchus (SMA) } \\
\hline Null & & & 1324 & 1728 & \\
\hline Size & 1 & 12.9 & 1323 & 1715 & $<0.01$ \\
\hline Region & 3 & 31.0 & 1320 & 1684 & $<0.01$ \\
\hline Sex & 1 & 0.1 & 1319 & 1684 & 0.76 \\
\hline \multicolumn{6}{|c|}{ Alopias superciliosus (BTH) } \\
\hline Null & & & 874 & 1212 & \\
\hline Size & 1 & 0.0 & 873 & 1212 & 0.95 \\
\hline Region & 3 & 4.9 & 870 & 1207 & 0.18 \\
\hline Sex & 1 & 1.0 & 869 & 1206 & 0.31 \\
\hline
\end{tabular}


Table 3. Multivariate logistic GLMs for the hooking mortality of the most frequently captured elasmobranch species: Prionace glauca, Pseudocarcharias kamoharai and Isurus oxyrinchus. Only the significant variables in each model were presented, with the respective standard error (SE) and statistical significance (Wald statistic and respective $p$-value). The odds-ratio estimates are calculated for an increase of $10 \mathrm{~cm}$ FL (continuous variable), and for each level of the categorical variables with reference to the baseline category. In Alopias superciliosus, differences in the hooking were not significant for any of the variables.

\begin{tabular}{|c|c|c|c|c|c|c|c|}
\hline \multirow{2}{*}{ Parameter } & \multicolumn{4}{|c|}{ Logistic GLM } & \multicolumn{3}{|c|}{ Odds-Ratio } \\
\hline & Estimate & SE & Wald Stat. & $p$-value & Estimate & Lower 95\% & Upper 95\% \\
\hline \multicolumn{8}{|c|}{ Prionace glauca $(\mathrm{BSH})$} \\
\hline Intercept & 0.65 & 0.10 & 6.61 & $<0.01$ & & & \\
\hline Size & -0.01 & 0.00 & -22.82 & $<0.01$ & 0.86 & 0.85 & 0.87 \\
\hline Region2 & 0.04 & 0.07 & 0.48 & 0.63 & 1.04 & 0.90 & 1.20 \\
\hline Region3 & 0.32 & 0.07 & 4.31 & $<0.01$ & 1.37 & 1.19 & 1.58 \\
\hline Region 4 & 0.70 & 0.06 & 11.09 & $<0.01$ & 2.01 & 1.78 & 2.28 \\
\hline SexM & 0.17 & 0.04 & 4.90 & $<0.01$ & 1.19 & 1.11 & 1.28 \\
\hline \multicolumn{8}{|c|}{ Pseudocarcharias kamoharai (PSK) } \\
\hline Intercept & -2.68 & 0.21 & -13.05 & $<0.01$ & & & \\
\hline Region3 & 1.04 & 0.20 & 5.06 & $<0.01$ & 2.82 & 1.89 & 4.21 \\
\hline Region4 & 0.61 & 0.25 & 2.45 & 0.01 & 1.84 & 1.13 & 2.99 \\
\hline SexM & 0.45 & 0.17 & 2.63 & 0.01 & 1.57 & 1.12 & 2.20 \\
\hline \multicolumn{8}{|c|}{ Isurus oxyrinchus (SMA) } \\
\hline Intercept & 0.58 & 0.39 & 1.49 & 0.14 & & & \\
\hline Size & -0.01 & 0.00 & -3.91 & $<0.01$ & 0.94 & 0.91 & 0.97 \\
\hline Region2 & -0.67 & 0.33 & -2.05 & 0.04 & 0.51 & 0.27 & 0.97 \\
\hline Region3 & -0.12 & 0.34 & -0.37 & 0.71 & 0.88 & 0.46 & 1.70 \\
\hline Region4 & 0.13 & 0.31 & 0.43 & 0.66 & 1.14 & 0.62 & 2.10 \\
\hline
\end{tabular}

The logistic models used in our study seem to be adequate for evaluating the contribution of potential explanatory variables (e.g., sex, region and specimen size) to the mortality odds-ratio estimates, even though the explanatory abilities of the final models are relatively low. For this study, we explored only those three possible explanatory variables, but others could be considered to further explain these hooking mortality rates. The time that each specimen spent on the longline after capture (not studied here - period between being hooked and being retrieved by the vessel crew) may significantly affect hooking mortality. After Morgan and Carlson (2010) who used hook timers for the US bottom longline fishery, the time the sharks spent on the bottom longline contributed significantly to explaining part of the hooking mortality, with positive relationships established for sandbar (Carcharhinus plumbeus), blacktip (Carcharhinus limbatus) and blacknose sharks (Carcharhinus acronotus). Diaz and Serafy (2005) and Morgan and Burgess (2007) have already shown a relationship in bottom longline fishery, or pelagic longlines, between fishing gear soak time and hooking mortality.

In our study, the blue shark and shortfin mako had decreasing odds of hooking mortality with increasing specimen size, meaning that the odds of a specimen surviving after being hooked were higher for larger specimens. At least for the blue shark, Diaz and Serafy (2005) and Campana (2009) reached similar conclusions.

The sex of the specimens and region of operation of the fishery also showed significant differences between the observed vs. expected proportions of dead vs. alive specimens for some of the species analysed. In blue shark, the odds of a male blue shark dying while hooked were higher than the odds for a female. However, a confounding effect between sex and size could occur, as significant differences were detected in the size distributions of male and female blue sharks. In the crocodile shark, in contrast, while males also showed significantly higher odds-ratio estimates of dying compared with the females, no significant differences were detected in the size distribution between sexes.

Several conservation and fisheries management options have been put forward, which include the mandatory release and prohibition of retention of particular vulnerable bycatch species. It is important to assess the impact of such measures by analysing what component of the bycatch are being captured and discarded dead. Current ICCAT management recommendations request mandatory discards of all bigeye threshers, hammerheads, oceanic whitetips and silky sharks. According to the results presented in this paper, it is possible to infer that, on average, at least $34 \%$ of the oceanic whitetip, $51 \%$ of the bigeye threshers, $56 \%$ of the silky sharks and $71 \%$ of the smooth hammerheads are being captured and discarded dead, meaning that even though the specimens are not retained, fishing mortality is still taking place at very high levels. Discarding practices need therefore to be assessed at a species-specific level. In the particular case of this fishery, such measures seem to be largely inefficient for some of the species (e.g., smooth hammerhead), but seem to be more efficient, for example, for the oceanic whitetip, where a higher proportion of the specimens captured are discarded alive.

This new information on the impacts of this longline fishery on pelagic elasmobranches can now be incorporated into further stock assessment models, including ecological risk assessment analysis. This also provides some insights on the efficiency of the recent ICCAT recommendations for mandatory discards of some elasmobranch species. 
Acknowledgements. Data and samples were collected within the scope of the EU Data Collection Framework, Project SELECTPAL (PROMAR 31-03-05-FEP-1) and Project THRESHER (FCT PTDC/MAR/109915/2009). The authors are grateful to the fishery observers Sérgio Amorim, Sérgio Goes, João Regala, Israel Ribeiro, Francisco Leitão and Marco Cerqueira for collecting the onboard data, and to the crews of the fishing vessels for assisting the observers during data collection. Joana Fernandez-Carvalho received a grant from FCT (Ref: BD 60624 /2009). Rui Coelho was supported by a grant from FCT (Ref: BPD 40523 / 2007), co-funded by "POCI2010, Programa Operacional Ciência e Inovação 2010" and "FSE, Fundo Social Europeu".

\section{References}

Afonso, A.S., Hazin, F.H.V., Carvalho, F., Pacheco, J.C., Hazin, H., Kerstetter, D.W., Murie, D., Burgess, G.H. 2011, Fishing gear modifications to reduce elasmobranch mortality in pelagic and bottom longline fisheries off Northeast Brazil. Fish. Res. 108, 336-343.

Arrizabalaga H., Bruyn P., Diaz G.A., Murua H., Chavance P., Delgado de Molina A., Gaertner D., Ariz J., Ruiz J., Kell L.T., 2011, Productivity and susceptibility analysis for species caught in Atlantic tuna fisheries. Aquat. Living Resour. 24, 1-12.

Buencuerpo V., Rios S., Moron, J., 1998, Pelagic sharks associated with the swordfish, Xiphias gladius, fishery in the eastern North Atlantic Ocean and the Strait of Gibraltar. Fish. Bull. 96, 667-685.

Campana S.E., Joyce W., Manning M.J., 2009, Bycatch and discard mortality in commercially caught blue sharks Prionace glauca assessed using archival satellite pop-up tags. Mar. Ecol. Prog. Ser. 387, 241-253.

Carruthers E.H., Schneider D.C., Neilson J.D., 2009, Estimating the odds of survival and identifying mitigation opportunities for common bycatch in pelagic longline fisheries. Biol. Conserv. 142, 2620-2630.

Coelho R., Santos M.N., Amorim S., 2012, Effects of hook and bait on targeted and bycatch fishes in an equatorial Atlantic pelagic longline fishery. Bull. Mar. Sci. 88, 449-467.

Cortés E., Arocha F., Beerkircher L., Carvalho F., Domingo A., Heupel M., Holtzhausen H., Santos M.N., Ribera M., Simpfendorfer C., 2010, Ecological risk assessment of pelagic sharks caught in Atlantic pelagic longline fisheries. Aquat. Living Resour. 23, 25-34.

Diaz G.A., Serafy J.E., 2005, Longline-caught blue shark (Prionace glauca): factors affecting the numbers available. Fish. Bull. 103, $720-724$.

Dulvy N.K., Baum J.K., Clarke S., Compagno L.J.V., Cortés E., Domingo A., Fordham S., Fowler S., Francis M.P., Gibson C., Martinéz J., Musick J.A., Soldo A., Stevens J.D., Valenti S., 2008, You can swim but you can't hide: the global status and conservation of oceanic pelagic sharks and rays. Aquat. Conserv. Mar. Freshw. Ecosyst. 18, 459-482.

Enever R., Catchpole T.L., Ellis J.R., Grant A., 2009, The survival of skates (Rajidae) caught by demersal trawlers fishing in UK waters. Fish. Res. 97, 72-76.

Hastie T., 2011, gam: generalized additive models. R package version 1.04.1. http://CRAN.R-project.org/package=gam.
ICCAT, 2009, Recommendation by ICCAT on the conservation of thresher sharks caught in association with fisheries in the ICCAT convention area. ICCAT Recommendation 2009-07. URL: http:// www.iccat.es/Documents/Recs/compendiopdf-e/2009-07-e.pdf.

ICCAT, 2010a, Recommendation by ICCAT on the conservation of oceanic whitetip shark caught in association with fisheries in the ICCAT convention area. ICCAT Recommendation 201007. URL: http://www.iccat.es/Documents/Recs/compendiopdf-e/ 2010-07-e.pdf.

ICCAT, 2010b, Recommendation by ICCAT on hammerhead sharks (family Sphyrnidae) caught in association with fisheries managed by ICCAT. ICCAT Recommendation 2010-08. URL: http://www. iccat.es/Documents/Recs/compendiopdf-e/2010-08-e.pdf.

ICCAT, 2011, Recommendation by ICCAT on the conservation of silky sharks caught in association with ICCAT fisheries ICCAT Recommendation 2011-08.

Mandelman J.W., Farrington M.A., 2007, The estimated short-term discard mortality of a trawled elasmobranch, the spiny dogfish (Squalus acanthias). Fish. Res. 83, 238-245.

Morgan A., Burgess G.H., 2007, At-vessel fishing mortality for six species of sharks caught in the northwest Atlantic and Gulf of Mexico. Gulf Carib. Res. 19, 123-129.

Morgan A., Carlson J.K., 2010, Capture time, size and hooking mortality of bottom longline-caught sharks. Fish. Res. 101, 32-37.

Moyes C.D., Fragoso N., Musyl M.K., Brill R.W., 2006, Predicting postrelease survival in large pelagic fish. Trans. Am. Fish. Soc. 135, 1389-1397.

Musyl M.K., Moyes C.D., Brill R.W., Fragoso N.M., 2009, Factors influencing mortality estimates in post-release survival studies. Mar. Ecol. Prog. Ser. 396, 157-159.

Musyl M.K., Brill R.W., Curran D.S., Fragoso N.M., McNaughton L.M., Nielsen A., Kikkawa B.S., Moyes C.D., 2011, Postrelease survival, vertical and horizontal movements, and thermal habitats of five species of pelagic sharks in the central Pacific Ocean. Fish. Bull. 109, 341-368.

Petersen S.L., Honig M.B., Ryan P.G., Underhill L.G., Compagno L.J.V., 2009, Pelagic shark by-catch in the tuna- and swordfishdirected longline fishery off southern Africa. Afr. J. Mar. Sci. 31, 215-225.

R Development Core Team, 2011, R: A language and environment for statistical computing. Version 2.13.0. R Foundation for Statistical Computing, Vienna, Austria. http://www.R-project.org.

Rodriguez-Cabello C., Fernández A., Olaso I., Sánchez F., 2005, Survival of small-spotted catshark (Scyliorhinus canicula) discarded by trawlers in the Cantabrian Sea. J. Mar. Biol. Assoc. UK 85, 1145-1150.

Smith S.E., Au D.W., Show C., 1998, Intrinsic rebound potentials of 26 species of Pacific sharks. Mar. Freshw. Res. 49, 663-678.

Stevens J.D., Bonfil R., Dulvy N.K., Walker P.A., 2000, The effects of fishing on sharks, rays, and chimaeras (Chondrichthyans), and the implications for marine ecosystems. ICES J. Mar. Sci. 57, 476-494.

Walsh W.A., Bigelow K.A., Sender K.L., 2009, Decreases in shark catches and mortality in the Hawaii-based longline fishery as documented by fishery observers. Mar. Coast. Fish. 1, 270-282.

Warnes G.R., Bolker B., Lumley T., Johnson R.C., 2011, gmodels: Various R programming tools for model fitting. R package version 2.15.1. http://CRAN.R-project.org/package=gmodels. 